\title{
Governança da água e Políticas de Gestão: o caso do comitê da bacia hidrográfica do
}

\section{rio das Velhas}

\author{
Water Governance and management Policies: the case of the rio das Velhas water basin committee \\ Políticas de Gobernanza y Gestión del agua: el caso del comité de la cuenca del río das Velhas
}

Recebido: 18/01/2022 | Revisado: 22/01/2022 | Aceito: 29/01/2022 | Publicado: 07/02/2022

\author{
Junea Jesus Lisboa Alves \\ ORCID: https://orcid.org/0000-0003-2529-1580 \\ Universidade Federal de Itajubá, Brasil \\ E-mail: junealisboalisboa@gmail.com \\ André Leal Rodrigues \\ ORCID: https://orcid.org/0000-0002-1656-3786 \\ Universidade Federal de Itajubá, Brasil \\ E-mail: andre_lealrodrigues@hotmail.com \\ Izabel Gonçalves Nogueira \\ ORCID: https://orcid.org/0000-0002-1924-8386 \\ Universidade Federal de Itajubá, Brasil \\ E-mail: izanog@gmail.com \\ Felipe Xavier \\ ORCID: https://orcid.org/0000-0003-2367-8060 \\ Universidade Federal de Itajubá, Brasil \\ E-mail: xavier.eng.pro@gmail.com \\ Roberto Cézar de Almeida Monte-Mor \\ ORCID: https://orcid.org/0000-0003-3158-6967 \\ Universidade Federal de Itajubá, Brasil \\ E-mail: montemor@unifei.edu.br
}

\begin{abstract}
Resumo
O modelo atual de gestão de recursos hídricos no Brasil deve ser integrado e descentralizado, conforme estabelece a Política Nacional de Recursos Hídricos. Esse modelo propõe uma gestão com a participação do poder público, da sociedade civil e dos usuários de cada bacia. O objetivo deste estudo foi avaliar a governança da água, especificamente em relação ao processo de descentralização, no que se refere a participação dos comitês de bacia hidrográfica, com foco no comitê da bacia hidrográfica do rio das Velhas (CBHVelhas). Sendo assim, para alcançar os objetivos deste artigo, foram feitas coletas e organização de dados secundários. Neste estudo, evidenciou que a CBHVelhas apesar de enfrentar muitas fragilidades, executa a maioria das funções que lhes são atribuídas. No entanto, percebeu que o comitê necessita de maior autonomia e de uma maior participação dos membros e da sociedade civil. Além disso, precisa de uma maior atuação nas decisões referentes a bacia do rio das Velhas. Assim, verificou-se, para que o processo de descentralização se concretize, são necessários o fortalecimento e a ampliação da representatividade das instituições nos comitês de bacia, com vistas nos trabalhos a serem desenvolvidos nas câmaras técnicas e a participação mais efetiva dos subcomitês na tomada de decisões.
\end{abstract}

Palavras-chave: Comitê de bacia hidrográfica; Bacia do rio das Velhas; Governança da água.

\begin{abstract}
The current model of water resources management in Brazil must be integrated and decentralized, as established by the National Water Resources Policy. This model proposes a management with the participation of the public authorities, civil society and the users of each basin. The objective of this study was to evaluate water governance, specifically in relation to the decentralization process, with regard to the participation of river basin committees, with a focus on the river basin committee of the rio das Velhas (CBHVelhas). Therefore, to achieve the objectives of this article, secondary data were collected and organized. In this study, it showed that CBHVelhas, despite facing many weaknesses, performs most of the functions assigned to them. However, he realized that the committee needs greater autonomy and greater participation by members and civil society. In addition, it needs to be more involved in decisions referring to the Velhas river basin. Thus, it was found that, for the decentralization process to materialize, it is necessary to strengthen and expand the representation of institutions in the basin committees, with a view to the work to be developed in the technical chambers and the more effective participation of subcommittees in the takeover of decisions.
\end{abstract}

Keywords: River basin committee; Basin of the Velhas river; Water governance. 


\begin{abstract}
Resumen
El modelo actual de gestión de los recursos hídricos en Brasil debe ser integrado y descentralizado, como lo establece la Política Nacional de Recursos Hídricos. Este modelo propone una gestión con la participación de las autoridades públicas, la sociedad civil y los usuarios de cada cuenca. El objetivo de este estudio fue evaluar la gobernanza del agua, específicamente en relación con el proceso de descentralización, en lo que respecta a la participación de los comités de agua de río, con un enfoque en el comité de agua de río (CBHVelhas). Por lo tanto, para lograr los objetivos de este artículo, se recopilaron y organizaron datos secundarios. En este estudio, mostré que CBHVelhas, a pesar de enfrentar muchas debilidades, realiza la mayoría de las funciones que se requieren. Sin embargo, se afirma que el comité necesita una mayor autonomía y una mayor participación de los miembros y la sociedad civil. Además, es necesario escuchar más sobre las decisiones relativas a la cuenca del río das Velhas. Así, se encontró que, para que el proceso de descentralización se materialice, es necesario fortalecer y ampliar la representación de las instituciones en los comités de cuenca, con miras al trabajo desarrollar en las cámaras técnicas y la participación más efectiva de las instituciones. subcomités en la toma de decisiones.
\end{abstract}

Palabras clave: Comité de Cuenca; Cuenca del río Velhas; Gobernanza del agua.

\title{
1. Introdução
}

A emergência das questões hídricas nas últimas décadas e, principalmente, a partir do início dos anos 2000 reflete uma série de preocupações em termos de suas fragilidades e potencialidades que demanda ser analisadas no campo acadêmico. Os recursos hídricos são, cada vez mais, considerados não apenas como bens naturais e insumos para as atividades produtivas, mas também como indicadores dos níveis de qualidade socioambiental presente nas regiões em que estão localizados (Theodoro et al., 2016).

Segundo Tundisi (2011), a água é um recurso estratégico e um bem comum que deve ser compartilhado por todos, entretanto, os usos múltiplos excessivos têm gerado uma menor disponibilidade da água, ocasionando problemas de escassez hídrica em muitos países. Esses diversos usos em uma mesma bacia hidrográfica, podem gerar alterações na qualidade ou quantidade da água e trazer conflitos entre os múltiplos usuários dos recursos hídricos. Portanto, é necessário que políticas públicas sejam realizadas. De acordo com Campos (2008 como citado em Campos \& Fracalanza., 2010), para que uma política pública se concretize, além da capacidade financeira, instrumental e operacional do estado, é preciso construir espaços nos quais tal política seja negociada de modo efetivo.

Em 1997, inspirada no modelo francês, foi implementada no Brasil a lei 9.433/1997 denominada Política Nacional de Recursos Hídricos (PNRH), onde consolidou a descentralização federal do gerenciamento do recurso hídrico, ressaltando que a gestão da água tem como unidade de atuação a bacia hidrográfica e deve proporcionar uso múltiplo das águas, de forma descentralizada e participativa (Brasil, 1997). Nesse contexto, os comitês de bacia assumem um papel essencial, na medida em que representam os usuários e a sociedade civil e elaboram os planos da bacia hidrográfica.

De acordo com Tundisi (2011), os comitês de bacia são fóruns com funções deliberativas e consultivas na esfera de cada bacia hidrográfica. Contam com a participação de todos os interessados na gestão das águas, como representantes do poder público - federal, estadual e municipal, dos usuários e da sociedade civil. Sendo assim, conforme (Denny et al., 2020), os comitês de bacia foram criados com o propósito de proporcionar a gestão descentralizada entre todos os órgãos e entidades atuantes na política de recursos hídricos, sendo considerado a instância mais importante de participação e integração do planejamento e das ações na área dos recursos hídricos.

Destaca-se que o comitê analisado neste artigo (CBH Rio das Velhas) é um dos órgãos responsáveis pela gestão descentralizada e participativa da bacia hidrográfica do rio das Velhas, tendo sido criado em 29 de junho de 1988, através do decreto estadual 36.692. Possui em sua estrutura grupos consultivos e propositivos, com atuação nas Unidades Territoriais Estratégicas (UTE) da bacia hidrográfica do rio das Velhas - denominado de Subcomitês. Os subcomitês são fundamentais na articulação local, uma vez que estabelecem e aproximam a representatividade das diversas regiões da bacia junto à plenária do comitê, a Diretoria e as Câmaras Técnicas (CBH Rio das Velhas [CBHVelhas], 2021). 
A bacia do rio das Velhas começou a sofrer na época do Ciclo do Ouro com a poluição produzida nos centros urbanos que utilizam os cursos d'água como destino para todo o tipo de esgoto e lixo, situação que foi agravada com o passar dos anos (CBHVelhas, 2021). Por drenar a região mais industrializada e densamente povoada de Minas Gerais, a Região Metropolitana de Belo Horizonte (RMBH), a bacia do rio das Velhas vem sofrendo acelerado e crescente processo de degradação. Segundo o CBHVelhas (2021), os principais impactos sofridos na bacia estão relacionados, principalmente, a poluição pelo despejo de esgotos domésticos e industrial não tratados, o desmatamento da vegetação ciliar, a atividade mineradora exercida na cabeceira da bacia, a retirada indiscriminada de água para projetos de irrigação, o aterro de veredas, várzeas, áreas alagáveis e lagoas marginais e a construção de barragens para aproveitamento hidrelétrico e acumulação de água para consumo humano. Essas práticas têm como consequências o aumento do assoreamento e alterações na qualidade da água do rio.

Em virtude disso e para alcançar a disponibilidade de água em quantidade e qualidade, visando garantir os múltiplos usos e a segurança hídrica, torna-se imprescindível uma boa governança da bacia do rio das Velhas. Neste contexto, os comitês de bacia representam um forte instrumento para o exercício da necessária governança dos recursos hídricos (Denny et al., 2020).

O objetivo deste trabalho foi apresentar uma análise sobre a gestão dos recursos hídricos e o poder da organização político-administrativa para a governança da água, realizando uma análise sobre a formação, legislação e funcionamento dos comitês de bacia, constatando que o processo da governança nesses comitês é condição indispensável para a efetiva implementação das políticas dos recursos hídricos, com foco no comitê da bacia hidrográfica do rio das Velhas.

\section{Metodologia}

Para alcançar os objetivos deste artigo, foram feitas coletas e organização de dados secundários. Realizou-se consultas a referências bibliográficas, livros, artigos, pesquisa documental, publicações governamentais, relatórios, decretos, legislações, dentre outros. Com relação a coleta de dados, a seleção dos artigos foi realizada por meio de ferramentas de busca, da seleção de palavras chave e de trabalhos que abordam governança e recursos hídricos no Brasil, conforme ilustrado no fluxograma da Figura 1.

Figura 1: Fluxograma da seleção e análise dos artigos.

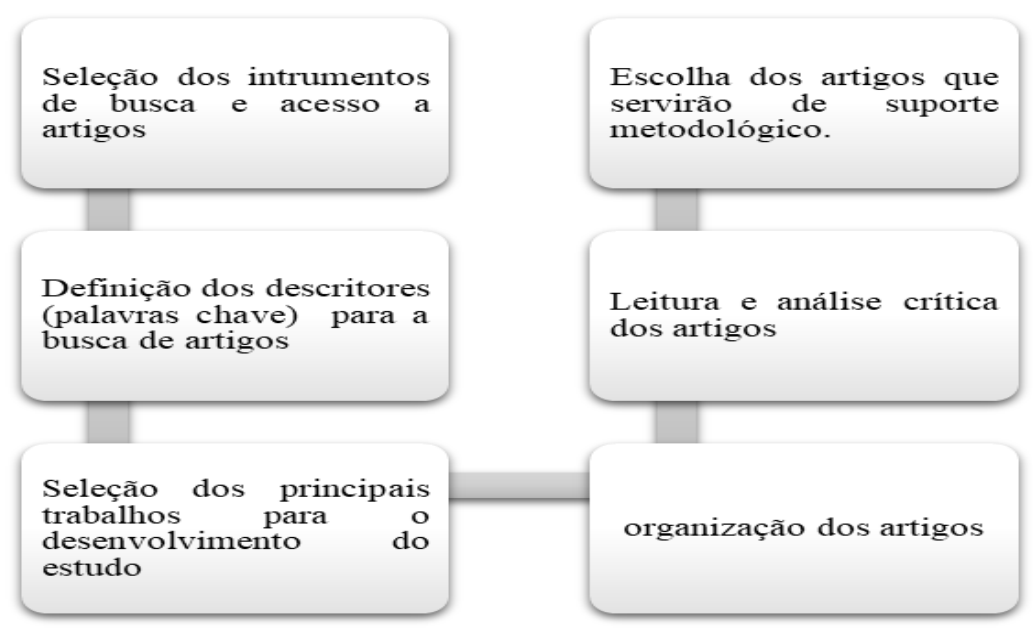

Fonte: Autores (2021).

Utilizou-se o Google acadêmico como o principal instrumento de pesquisa. Realizou a busca utilizando palavraschave, tais como: Governança da água, recursos hídricos, Comitê de bacia do rio das Velhas, conflitos da água, Gestão de Recursos hídricos e Bacia do rio das Velhas. Dentre os materiais secundários, tomou-se como suportes para o desenvolvimento 
desse estudo as publicações "Dinâmica Territorial, transformações ambientais e implicações no manancial de abastecimento público da Região Metropolitana de Belo Horizonte-bacia hidrográfica do rio das Velhas, Minas Gerais" e “A institucionalização da Gestão de Recursos Hídricos na Bacia Hidrográfica do Rio das Velhas, Minas Gerais, Brasil, sob a ótica democrática e participativa", pesquisas realizadas respectivamente pelos autores (Lemos \& Magalhães, 2019) e Theodoro et al. (2016). Além disso, outra fonte de consulta bastante referenciada, com informações chave e de suma importância para o desenvolvimento deste estudo foi o CBHVelhas (2021).

\subsection{Caracterização da bacia hidrográfica do rio das Velhas}

A bacia hidrográfica do rio das Velhas, conforme representada na Figura 2, está localizada na região central do Estado de Minas Gerais, entre as latitudes $17^{\circ} 15^{\prime} \mathrm{S}$ e $20^{\circ} 25^{\prime} \mathrm{S}$ e longitudes $43^{\circ} 25^{\prime} \mathrm{W}$ e $44^{\circ} 50^{\prime} \mathrm{W}$, apresenta forma alongada e inclinada predominantemente na direção norte-sul, é correspondente a Unidade de Planejamento e Gestão de Recursos Hídricos (UPGRH). O rio das Velhas tem sua nascente principal na cachoeira das Andorinhas, no município de Ouro Preto, numa altitude de aproximadamente 1.500 metros. Toda a bacia compreende uma área de $27.850 \mathrm{~km}^{2}$, nos quais o rio principal percorre uma distância de 806,84 km, desaguando no rio São Francisco, em Barra do Guaicuí, Distrito de Várzea da Palma (CBHVelhas, 2021).

Figura 2: Mapa de localização da bacia hidrográfica do rio das Velhas.
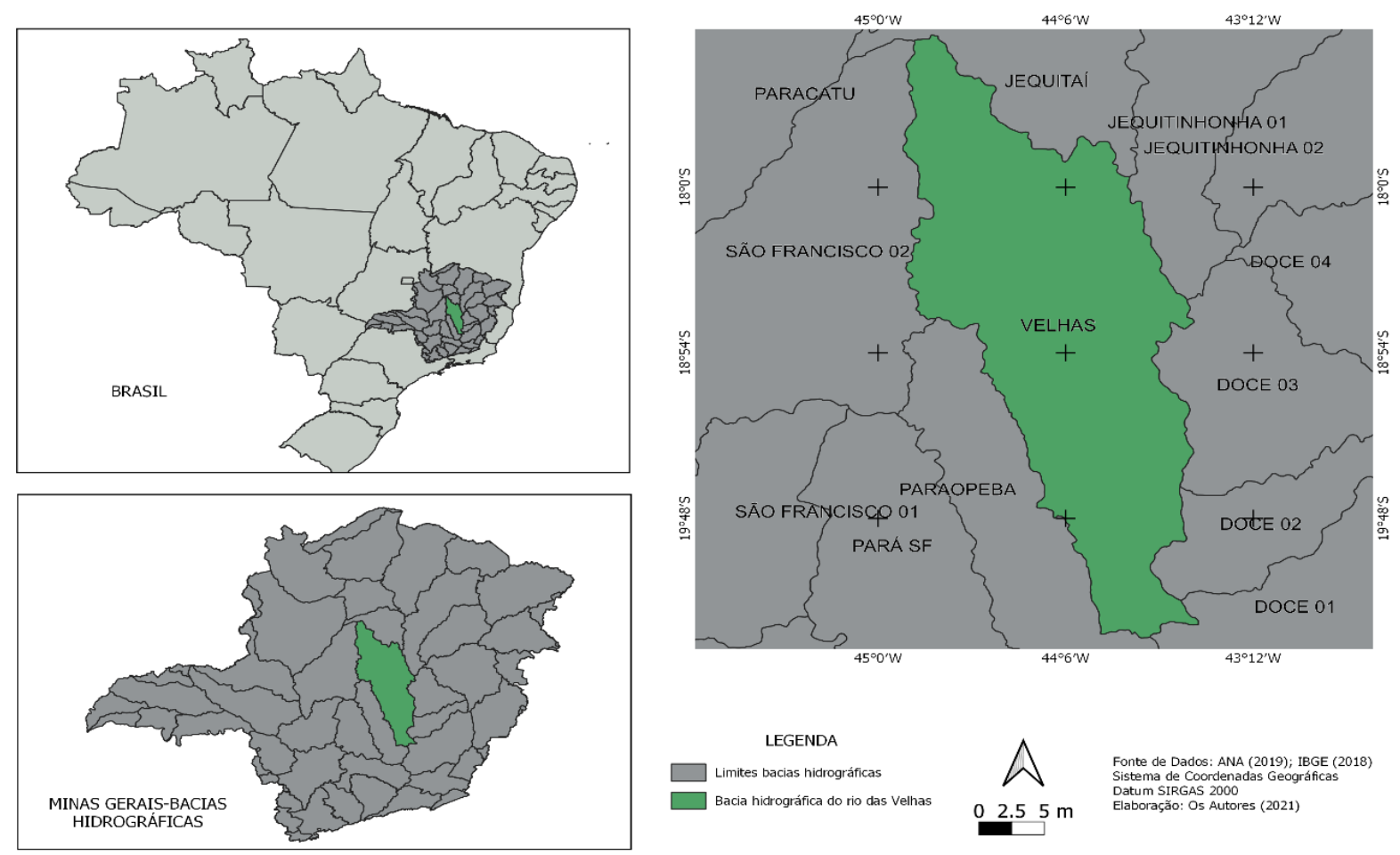

Fonte: Elaborado pelos Autores (2021).

O território da bacia é subdividido em quatro macrorregiões conforme mostra a Figura 3, e 23 Unidades Territoriais que são os territórios das sub-bacias. A região denominada de baixo rio das Velhas é composta por oito municípios, representando a segunda maior região $\left(31 \%, 8.630,07 \mathrm{~km}^{2}\right)$ e, nenhum desses municípios têm a área do território totalmente inserido na bacia (CBHVelhas, 2021). 
O médio baixo rio das Velhas possui 23 municípios inseridos total ou parcialmente e, dentre os que possuem todo o seu território inserido na bacia estão Araçaí, Cordisburgo, Gouveia, Inimutaba, Monjolos, Presidente Juscelino, Presidente Kubitschek, Santana de Pirapama, Santana do Riacho e Santo Hipólito (CBHVelhas, 2021). As UTEs que estão compreendidas dentro dessa macrorregião são: Peixe Bravo, Ribeirão Tabocas e Onça, Santo Antônio-Maquiné, Rio Cipó, Rio Paraúna, Ribeirão Picão e Rio Pardo.

A macrorregião do médio alto rio das Velhas compreende 20 municípios e, dentre estes, Capim Branco, Confins, Funilândia, Lagoa Santa, Matozinhos, Nova União, Pedro Leopoldo, Prudente de Morais, Ribeirão das Neves, São José da Lapa, Taquaraçu de Minas e Vespasiano estão totalmente inseridos na bacia (CBHVelhas, 2021). As UTEs que compõem essa macrorregião são: Poderoso Vermelho, Ribeirão da Mata, Rio Taquaraçu, Carste, Jabo/Baldim e Ribeirão Jequitibá.

O alto rio das Velhas é composto por 10 municípios na área denominada Quadrilátero Ferrífero, e, dentre estes, os municípios que estão totalmente inseridos na região do alto rio das Velhas são: Belo Horizonte, Itabirito, Nova lima, Raposos e Rio Acima (CBHVelhas, 2021). As Unidades Territoriais Estratégicas (UTEs) que compõem o alto rio das Velhas são: Nascentes, Rio Itabirito, Águas do Gandarela, Água da Moeda, Ribeirão Caeté/Sabará, Ribeirão Arrudas e Ribeirão Onça.

Figura 3: Subdivisão das macrorregiões do território da bacia do rio das Velhas.

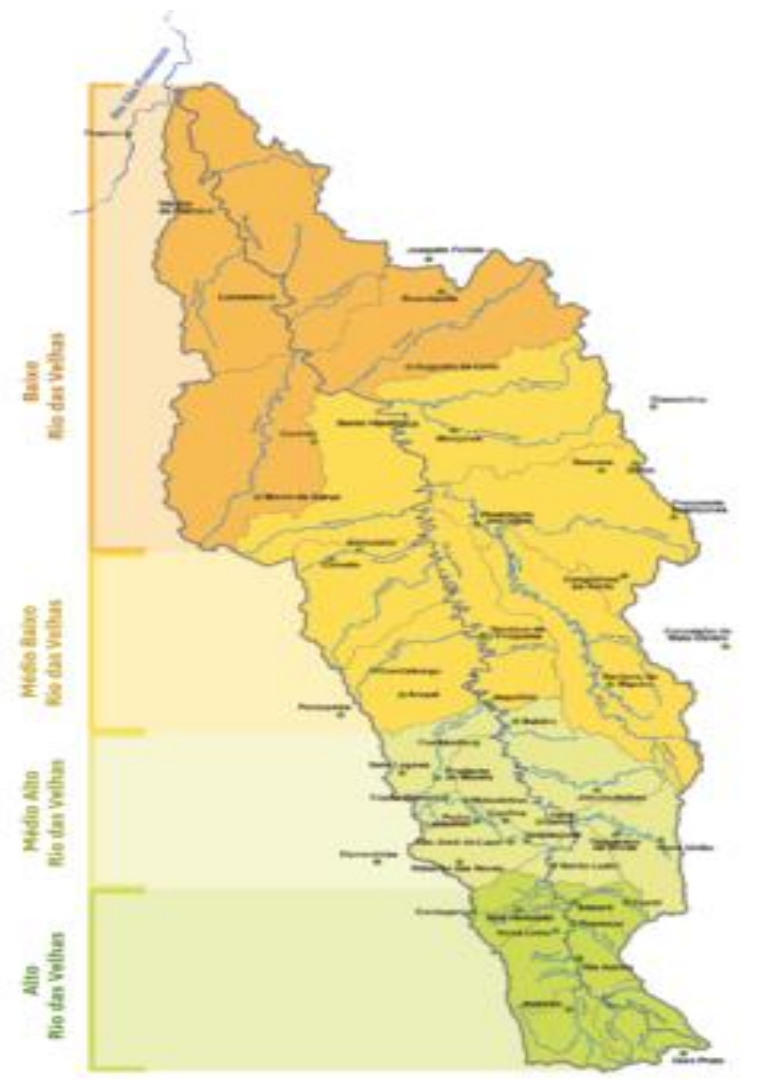

Fonte: CBHVelhas (2021). 


\section{Resultados e Discussão}

\subsection{Gestão das Águas}

\subsubsection{Governabilidade e Governança}

A governabilidade está relacionada às condições sistêmicas gerais sob as quais se dá o poder em uma sociedade. Já a governança, conforme Trindade et al. (2018), no âmbito dos recursos hídricos, compreende os aspectos políticos, econômicos, sociais e administrativos desenvolvidos para gerenciar os corpos d'água.

A Organização para a cooperação e desenvolvimento econômico (OCDE, 2015) afirma que, para lidar com os desafios atuais e futuros em relação a crise da água são necessárias políticas públicas mais robustas, e, neste caso, a governança da agua poderá contribuir de forma significativa para a concepção e implementação dessas políticas, envolvendo uma responsabilidade partilhada entre diferentes entes governamentais, sociedade civil, empresas e o mais alargado conjunto de partes interessadas que tenham um papel importante a desempenhar ao lado dos decisores políticos para que se colham os benefícios econômicos, sociais e ambientais de uma boa governança da água.

De acordo com a Agência Nacional de Água (ANA, 2011) a insuficiência de uma boa governança, que inclui as políticas inoperantes, fiscalização precária, instituições fracas, falta de infraestrutura adequada e a escassez de novos investimentos para a capacitação de recursos humanos contribuem para o aumento de problemas relacionados à qualidade da água.

Atualmente, acredita-se que a crise de água existente está mais relacionada a gestão inadequada dos recursos hídricos do que propriamente a escassez hídrica, e nesse aspecto, tem se discutido bastante sobre a definição de governança da água, correlacionando- a com a participação dos atores sociais, instituições e agentes governamentais responsáveis pela tomada de decisões quanto ao uso dos recursos hídricos e por uma gestão eficaz.

No Brasil, a gestão dos recursos hídricos possui um caráter federativo onde ocorre, principalmente, por meio da unidade de planejamento e da bacia hidrográfica, e nesse cenário, o comitê de bacia hidrográfica ( $\mathrm{CBH})$ é considerado como um interventor na ampliação da democracia e da participação coletiva, devido às suas inerentes características. No caso específico da CBH Rio das Velhas o modelo é considerado quadripartite, uma vez que ocorre uma divisão entre o poder público municipal e estadual, possibilitando maior participação ao poder local, que possui método de atuação diferente da regional (Theodoro, 2017).

Segundo Theodoro et al. (2016) o comitê da bacia hidrográfica do rio das velhas, por ser um dos mais antigos do país e também pertencer a capital do estado federal (Belo Horizonte) lhe confere um caráter diferenciado no contexto da governança a ser exercida, uma vez que conjuntamente com a bacia hidrográfica do rio Paraopeba tem se a mais rica e populosa região metropolitana de Minas Gerais.

O CBHVelhas, segundo o Instituto Mineiro de Gestão das águas (IGAM, 2021), possui quatro instrumentos de gestão da política estadual de recursos hídricos (PERH), conforme mostra o Quadro 1. Desses, três já foram implantados e/ou concluídos e um está em fase de implementação. 
Quadro 1: Instrumentos de Gestão da PERH - CBHVelhas.

\begin{tabular}{|l|l|l|l|}
\hline \multicolumn{1}{|c|}{ Instrumentos de Gestão } & \multicolumn{1}{|c|}{ Conceito } & \multicolumn{1}{|c|}{ Situação } \\
\hline $\begin{array}{l}\text { Plano Diretor de Recursos } \\
\text { Hídricos (PDRH, 2015). }\end{array}$ & $\begin{array}{l}\text { Apresenta um diagnóstico da situação atual do rio das Velhas, da qualidade e } \\
\text { quantidade das suas águas, dos instrumentos de gestão, da organização do } \\
\text { sistema de gerenciamento de recursos hídricos, indicando falhas, problemas, } \\
\text { déficit, mas principalmente orientações e direções a serem tomados. }\end{array}$ & Concluído/Atualizado \\
\hline $\begin{array}{l}\text { Enquadramento dos } \\
\text { corpos de água segundo } \\
\text { os usos preponderantes }\end{array}$ & $\begin{array}{l}\text { Visa assegurar às águas qualidade compatível com os usos mais exigentes a } \\
\text { que forem destinadas, bem como reduzir os custos de combate à poluição, } \\
\text { mediante ações preventivas permanentes. }\end{array}$ & Vigente \\
\hline $\begin{array}{l}\text { Outorga de direito de uso } \\
\text { dos recursos hídricos }\end{array}$ & $\begin{array}{l}\text { Assegura ao usuário o direito de utilizar os recursos hídricos e o efetivo } \\
\text { exercício dos direitos de acesso à água, bem como a garantia dos múltiplos } \\
\text { usos nas bacias hidrográficas. }\end{array}$ & Implementada \\
\hline $\begin{array}{l}\text { Cobrança pelo uso de } \\
\text { recursos hídricos }\end{array}$ & $\begin{array}{l}\text { Visa ao reconhecimento da água como um bem ecológico, social e } \\
\text { econômico, dando ao usuário uma noção de seu real valor. Objetiva também } \\
\text { arrecadar recursos financeiros para o financiamento de programas e } \\
\text { intervenções previstos no PDRH da Bacia Hidrográfica, voltados para a } \\
\text { melhoria da quantidade e da qualidade da água. }\end{array}$ & Implada \\
\hline $\begin{array}{l}\text { Sistema de Informação } \\
\text { em recursos hídricos }\end{array}$ & $\begin{array}{l}\text { Coleta, trata, armazena, recupera, disponibiliza e divulga as informações que } \\
\text { subsidiam a gestão dos recursos hídricos. }\end{array}$ & Em implementação \\
\hline
\end{tabular}

Fonte: IGAM (2021). Adaptada pelos Autores (2021).

Dentre estes instrumentos, destaca-se o Plano diretor de recursos hídricos (PDRH) como um instrumento indispensável para a gestão das águas no âmbito do comitê de bacia. O PDRH traz como estratégias para os instrumentos de gestão dos recursos hídricos diversas diretrizes, dentre elas, as diretrizes de integração dos instrumentos de gestão de recursos hídricos. De acordo com o PDRH a bacia do rio das Velhas já possui os principais instrumentos de gestão de recursos hídricos previstos na legislação implementados, no entanto, alguns ainda na fase inicial e com um precário controle de informações gerenciais. Entre uma das metas do plano está o de integrar procedimentos de outorga aos de licenciamento ambiental aumentando o controle da CBHVelhas sobre a gestão de recursos hídricos na bacia, para que no rio das Velhas possa ser possível a pesca, a natação e a navegação. Uma outra diretriz está relacionada a restrição da concessão de novas outorgas a capacidade de suporte do rio das velhas, sendo uma da atividade proposta a integração de procedimentos de concessão de licenças ambientais e de outorgas de uso da água com os objetivos do PDRH e com o sistema de informação de recursos hídricos, fortalecendo o comitê das velhas como gestor de recursos hídricos na bacia.

\subsubsection{Gestão de Conflitos}

A disponibilidade de água é indispensável a existência de vida no planeta. As características da água tanto quantitativas quanto qualitativas condicionam os atos de sobrevivência, qualidade de vida, crescimento econômico e de desenvolvimento de territórios. Por possuir uma condição estratégica, ser um elemento finito e irregularmente distribuídos no tempo e no espaço, os recursos hídricos são alvos de tensões e disputas, muitas vezes, difícil e que demandam diferentes níveis de análise para o seu entendimento (Ribeiro et al., 2018). Quando há escassez de água, verifica-se, geralmente, conflitos dos recursos hídricos. Sendo assim, Ribeiro et al. (2018), descreve que:

"Em determinadas regiões, os recursos hídricos já são considerados insuficientes para o atendimento das demandas sociais. Nessas áreas, a perspectiva de uma situação de conflito pelo uso de recursos hídricos pode apresentar diferentes percepções sociais e ser entendida a partir de diferentes pressupostos e variados instrumentos e técnicas. Um caminho possível de análise é tentar entender a dinâmica de conflito a partir das perspectivas normativas e legais, que dão suporte às estruturas de gestão e de planejamento. Outra forma pode ser a partir do entendimento social que diferentes atores e gestores percebem no território e nos diferentes usos de recursos hídricos. A concepção de conflito 
pela água, portanto, assume diferentes perspectivas em função do ponto de vista e dos diferentes aspectos sociais, ambientais e econômicos. (Ribeiro et al., 2018).”

Moreira et al. (2018) ressalta que, os conflitos pelo uso da água podem se dar em decorrência de construção de obra hídrica, o que, neste caso, irá envolver outros aspectos, dentre eles os direitos sociais além do direito ao acesso à água, da limitação desse recurso, ou em virtude de uma gestão hídrica ineficaz e/ou escassez hídrica, dentre outros fatores.

Um dos papeis dos comitês de bacia hidrográfica é atuar na arbitragem dos conflitos na sua área de atuação. No caso do comitê da bacia hidrográfica do rio das Velhas, essa atribuição é determinada, também, pelo decreto 39.692/1998 que instituiu o comitê da bacia hidrográfica do rio das Velhas.

A bacia do rio das Velhas, principalmente o alto rio das Velhas, está sofrendo, segundo o CBHVelhas (2021), uma situação de superexploração e vulnerabilidade, podendo ocasionar problemas futuros, uma vez que o rio das velhas é responsável pelo abastecimento de mais de 60\% da população da capital e de 50\% dos mais de 5 milhões de habitantes da região metropolitana de Belo Horizonte, além de suas águas serem utilizadas para as atividades de irrigação, industrias, minérios e outros múltiplos usos da bacia.

A margem esquerda do rio das Velhas é o que apresenta as maiores áreas com processo de ocupação de intensas modificações antrópicas, principalmente mineração e usos urbanos. A mineração e o usos urbanos foram os dois principais tipos de ocupação a se intensificarem, principalmente, no alto rio das Velhas, durante o período de 1987 a 2017 (Lemos \& Magalhães, 2019).

Sendo assim, Lemos e Magalhães (2019), afirma que, por essas atividades serem consideradas de alto impacto para os ecossistemas aquáticos, verificou-se que a intensificação da ocupação urbana no alto rio das Velhas teve efeito direto na disponibilidade hídrica e na qualidade da água. Diante disso, juntamente com outros fatores, a bacia do rio das Velhas é caracterizada pelo conflito de uso inadequado do solo, ocupação desordenada e má gestão dos recursos hídricos ao longo de todo seu território.

De acordo com Magalhães e Lopes (2017), a mudança no regime pluviométrico, atrelada a má gestão dos recursos hídricos tem causado inúmeros problemas nos ecossistemas aquáticos em diversos estados brasileiros, inclusive no estado de Minas Gerais. Segundo o CBHVelhas (2021), a redução no volume das chuvas e diminuição da vazão dos rios trouxeram dificuldades na região, gerando conflitos pelo uso da água, principalmente na parte alta do rio das Velhas. Os principais focos de conflito, conforme informa o CBHVelhas (2021), estão relacionados a oferta e demanda da água, conflitos de interesses distintos pelo uso da água relacionados a mineração, agronegócio, silvicultura, agropecuária, irrigação e expansão industrial em algumas localidades.

$\mathrm{O}$ alto rio das Velhas possui uma intensa pressão de atividades que afetam a qualidade e quantidade da água, dentre essas atividades, segundo o CBHVelhas (2021), estão o uso e ocupação do solo, atividade industrial, expansão de atividades imobiliárias, intensa atividade de mineradoras, áreas degradadas, focos erosivos, ausência de mata ciliar, atividades agropecuárias, expansão imobiliária, aumento da urbanização e presença de voçorocas gerando impactos nos corpos hídricos.

Um outro grande problema relatado pelo CBHVelhas (2021) é o rebaixamento do lençol freático pela mineração. Além disso, há trechos onde ocorre um crescente aporte de sedimentos e esgotos sem tratamento, despejados diretamente no corpo d'água, com o aporte de cargas difusa, o que afeta, diretamente, a qualidade da água da bacia. O alto rio das Velhas é responsável pelo abastecimento da região metropolitana de Belo Horizonte, assim, existe uma extrema preocupação pela manutenção da qualidade e quantidade de água. No entanto, verifica-se consequências geradas, principalmente, pela atividade minerária e o adensamento populacional que acabam por afetar essas águas. Observa-se que a região, denominada de UTE Ribeirão da Onça é o que apresenta a maior concentração populacional da bacia do rio das Velhas, e, dentre as unidades territoriais, segundo o CBHVelhas (2021) é uma das que apresenta um alto nível de degradação das suas águas, provavelmente, 
devido a presença de ocupações irregulares no entorno da bacia, apresentando uma carência de infraestrutura sanitária e urbanística básica. Dessa forma, verifica-se a necessidade de políticas públicas eficazes, realizado de forma multidisciplinar, inclusive, com a cooperação dos municípios durante o processo de recuperação do rio das Velhas.

Atualmente, conforme o IGAM (2021), foi estabelecido um acordo que prevê ações conjuntas para garantir a segurança hídrica na Região Metropolitana de Belo Horizonte (RMBH). Segundo o IGAM (2021), o acordo pretende ampliar a capacidade de resiliência da região do alto rio das Velhas e promover a manutenção dos ecossistemas aquáticos. $\mathrm{O}$ acordo foi assinado pelo IGAM, Instituto Estadual de Florestas (IEF), Secretaria de Estado de Meio Ambiente e Desenvolvimento Sustentável (SEMAD), Companhia de Saneamento de Minas Gerais (COPASA), CBH Rio das Velhas, Agência de Bacia Hidrográfica Peixe Vivo e a Agência de Desenvolvimento da Região Metropolitana de Belo Horizonte. Segundo o IGAM (2021), estão entre as medidas previstas no acordo, assinado no dia 25 de novembro de 2021:

"Entre as medidas previstas estão o desenvolvimento de ações estruturais e intervenções físicas em microbacias prioritárias como, por exemplo, a construção de bacias de captação ao longo das estradas rurais; ações de manejo e conservação do solo como o terraceamento e barraginhas; a recuperação de áreas degradadas e de voçorocas prioritárias na sub-bacia do Rio Maracujá, em Ouro Preto; restauração ecológica; revitalização e proteção de nascentes e matas ciliares e áreas de recarga hídrica, além de outras ações que promovam a recarga dos lençóis subterrâneos. Ainda estão previstas ações estruturantes, medidas e diretrizes que visem o aprimoramento do sistema de gerenciamento dos recursos hídricos, gestão ambiental, planejamento territorial e estratégico no abastecimento público (IGAM, 2021)."

O médio alto rio das Velhas possui diferentes atividades que afetam os cursos d'água, dentre elas, segundo o CBHVelhas (2021), estão a agropecuária, desmatamentos aliados ao superpastoreio, abertura de estradas vicinais com perdas de solo e diminuição do reabastecimento do lenço freático, uso e ocupação desordenada do solo, expansão urbana e industrial, pastagens, exploração de culturas e atividades minerárias. Além disso, há um déficit em relação ao tratamento de esgotos, tanto doméstico quanto industrial. Para mitigar esses problemas, faz-se necessária a ampliação de tratamento de efluentes, investimentos em programas de recuperação e conservação dos corpos hídricos, inclusive com o controle de cargas difusas.

O médio baixo rio das velhas é caracterizado com situações territoriais conflituosas muito próximas ao "baixo rio das velhas" os conflitos pelo uso da água existentes se configuram em torno das grandes fazendas voltadas para a atividade do agronegócio, silvicultura, agropecuária e irrigação e expansão industrial em algumas localidades (CBHVelhas, 2021).

Segundo Lemos e Rocha (2013), a água, pelos seus múltiplos usos, é alvo constante de conflitos e por isso, certas atividades industriais se implantadas, por exemplo, à montante de uma captação de água podem comprometer todo o abastecimento de uma cidade, da mesma forma, em uma área rural poderá comprometer as atividades de irrigação. Portanto, é necessário garantir a disponibilidade de água e a conciliação com as diferentes atividades. Dessa forma, é imprescindível diversas ações, entre elas, a utilização dos instrumentos de gestão de outorga. O instrumento de gestão de outorga é indicado para mapear e cadastrar os usos da água.

No Estado de Minas Gerais, observa-se um déficit no que se contempla a gestão das outorgas, reflete em um território onde a gestão pública não consegue acompanhar o crescimento desordenado e as pressões de degradação ambiental como desmatamento do cerrado, o soterramento de nascentes e práticas agrícolas inadequadas, o que prejudica a manutenção dos mananciais hídricos. Também se caracteriza por ser uma região de escassez hídrica e estar sofrendo com as mudanças climáticas e a falta de regularidade da chuva, aumentando assim a insegurança hídrica.

Necessita-se de regulamentação e planejamento para os recursos hídricos nas bacias hidrográficas. A outorga para uso dos recursos hídricos é um dos instrumentos mais importantes e que faz parte do planejamento. Ela é o fator essencial de regulamentação legal do uso hídrico a partir do enquadramento e que, consequentemente, permite a realização dos cálculos necessários para o estabelecimento da cobrança pelo uso requerido, sendo fundamental para a instalação de empreendimentos 
produtivos e para a regulação ambiental e hídrica consultiva e não-consultiva. Entretanto, de forma geral, observa-se que o arranjo jurídico é muito amplo para se realizar a gestão de forma simplificada e em apenas uma esfera de decisão.

O que se percebe é que a situação de conflito pelo uso de recursos hídricos na bacia do rio das Velhas é reconhecida pelo CBHVelhas, tanto em documentos e registros oficiais, quanto na percepção social dos diferentes atores sociais. Este reconhecimento ocorre principalmente com a preocupação manifesta de uma situação de insegurança hídrica.

\subsubsection{Comitê da bacia hidrográfica do rio das Velhas- CBHVelhas}

O Comitê da bacia hidrográfica do rio das Velhas (CBHVelhas) foi criado a partir do decreto estadual $\mathrm{n}^{\circ} 39.692$, de 29 de junho de 1998, ano em que surgiram os primeiros comitês mineiros. A finalidade do CBHVelhas é definida pelo decreto 36.692/1988:

"Fica instituído o Comitê da Bacia Hidrográfica do Rio das Velhas, com a finalidade de promover, no âmbito da gestão de recursos hídricos, a viabilização técnica e econômico-financeira de programa de investimento e consolidação de política de estruturação urbana e regional, visando ao desenvolvimento sustentado da Bacias. (Minas Gerais, 1988)."

Desde então, o comitê originado discute e delibera assuntos referentes aos usos da água e à qualidade ambiental da bacia do rio das Velhas. É considerado um dos Comitês precursores na implementação dos instrumentos de gestão e, consequentemente, da gestão descentralizada e participativa em seu território.

O CBHVelhas surgiu em um momento em que o contexto da gestão institucional de recurso hídrico havia passado por sua primeira grande reforma desde o arcabouço jurídico de 1934, quando da promulgação da Lei Federal n 9.433 de 1997 (CBHVelhas, 2021). Essa nova estruturação na forma como a gestão era pensada, de um sistema burocratizado para um sistema mais participativo e democrático, foi essencial para que existisse um ambiente jurídico mínimo propício para que organismos de bacia surgissem. Tanto que logo após a origem do CBHVelhas em 1998, houve a promulgação da Política Estadual de Recursos Hídricos via a Lei Estadual n 13.199, de 1999.

Criado para coordenar o uso dos recursos hídricos de forma integrada e descentralizada com a cooperação, inclusive, da sociedade, o CBHVelhas é um órgão colegiado que emite pareceres, institui resoluções e toma decisões com a missão, conforme apresentadas no Quadro 2, de construir uma proposta sustentável para o território da bacia. Devido ser considerado um avanço da democracia participativa, o CBHVelhas, assim como os outros comitês do país são, comumente, chamados de "parlamento das águas" conforme mostra Figura 3. 
Figura 3: Comitê de Bacia Hidrográfica (Parlamento das águas).

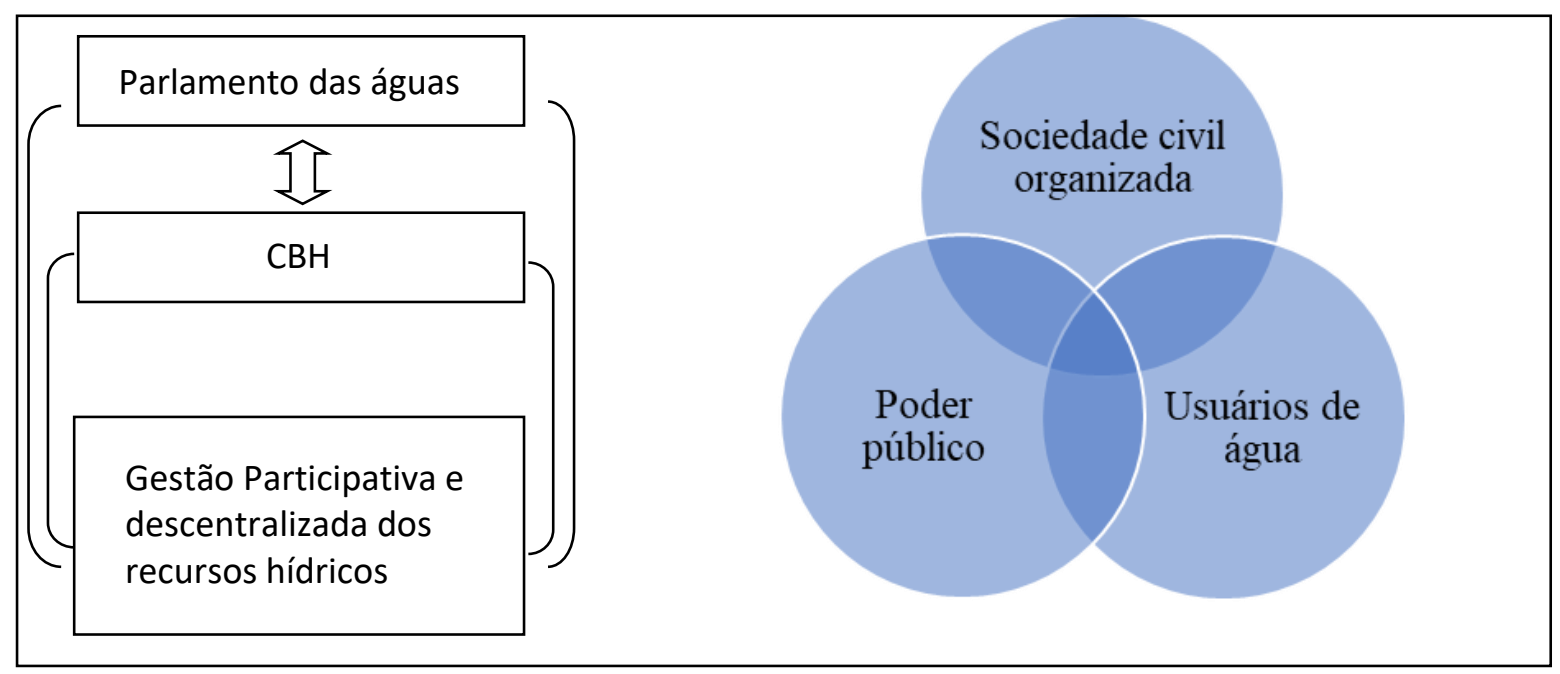

Fonte: CBHVelhas (2021). Adaptada pelos Autores (2021).

Quadro 2: Princípios e missão do Comitê da bacia hidrográfica do rio das Velhas - CBHVelhas.

\begin{tabular}{|c|c|}
\hline Princípio I & $\begin{array}{l}\text { Promover constante e estreita relação orgânica e dialógica com o Comitê da Bacia Hidrográfica do Rio São Francisco, } \\
\text { com o Fórum Mineiro de Comitês e demais comitês de Bacia do Brasil a fim de promover e fortalecer a política } \\
\text { nacional de recursos hídricos, a gestão ambiental por bacia hidrográfica e a autonomia decisória dos comitês. }\end{array}$ \\
\hline Princípio II: & $\begin{array}{l}\text { Zelar pela efetividade do da gestão tripartite, fortalecendo a participação da sociedade civil no processo decisório, e } \\
\text { mantendo a sua autonomia decisória dentro dos preceitos legais. }\end{array}$ \\
\hline Princípio III: & $\begin{array}{l}\text { Priorizar, no exercício de suas atividades de gestão e gerenciamento, a elaboração, efetivação e as atualizações de seu } \\
\text { Plano de Bacia, que consiste no principal elemento a orientar e fundamentar a implementação dos demais instrumentos } \\
\text { da Política Estadual de Recursos Hídricos, de forma integrada com as diretrizes do Sistema Estadual de } \\
\text { Gerenciamento de Recursos Hídricos e do Sistema Estadual de Meio Ambiente. }\end{array}$ \\
\hline Princípio IV: & $\begin{array}{l}\text { Implementar no Plano de Bacia um conjunto de programas estratégicos e operacionais visando a revitalização da } \\
\text { bacia, a partir de um plano de Metas, com o objetivo final de navegar, pescar e nadar ao longo de toda a extensão do } \\
\text { rio, garantindo através de um modelo de sustentabilidade ambiental, econômica e social a biodiversidade aquática, a } \\
\text { qualidade e quantidade das águas, para esta e as futuras gerações que habitam a bacia. }\end{array}$ \\
\hline Princípio V: & $\begin{array}{l}\text { Exercer amplamente o seu papel institucional e político no sentido de estabelecer um diálogo e uma integração com } \\
\text { todos os demais entes que compõem o Sistema de Recursos Hídricos com o objetivo de integrar o licenciamento } \\
\text { ambiental com a gestão das águas, considerando que a qualidade e a quantidade apresentam uma interdependência } \\
\text { com a sustentabilidade dos ecossistemas da bacia, com sua biodiversidade e o bem-estar social, sendo a água um bem } \\
\text { natural, social e essencial à vida, que por sua escassez e fatores inerentes à sua gestão, adquire valor econômico. }\end{array}$ \\
\hline Princípio VI: & $\begin{array}{l}\text { Adotar firmes atitudes éticas em defesa do interesse público pelas águas, pela revitalização, preservação e conservação } \\
\text { dos ecossistemas e da biodiversidade da bacia. }\end{array}$ \\
\hline Princípio VII: & $\begin{array}{l}\text { Buscar, junto ao Conselho Estadual de Recursos Hídricos (CERH) e ao Conselho Estadual de Política Ambiental } \\
\text { (COPAM) propor atos normativos, com vistas ao aperfeiçoamento do sistema democrático de gestão sustentável das } \\
\text { águas no território da bacia hidrográfica do rio das Velhas. }\end{array}$ \\
\hline Princípio VIII: & $\begin{array}{l}\text { Comprometer com a plena implementação e efetividade dos Instrumentos de Gestão de Recursos Hídricos previstos na } \\
\text { legislação, de maneira que possam ser eficazes na preservação dos recursos hídricos e ambientais da bacia, } \\
\text { mobilizando todos atores numa pactuação pelas águas na bacia. }\end{array}$ \\
\hline
\end{tabular}

Fonte: CBHVelhas (2021). Adaptada pelos Autores (2021).

O CBHVelhas demonstra possuir diversos conflitos organizacionais que não são revelados claramente, tanto em sua dinâmica quanto em seu organograma. Conseguir estabelecer relações entre os principais conflitos entre seus participantes poderá favorecer o entendimento de como melhorar processos de tomada de decisão em ambiente difuso e complexo como o de um comitê de características tão próprias e com formação muito heterogênea. Especificamente sobre os conflitos relacionados ao rio das Velhas, cabe ressaltar que a região continua sendo um local de disputas políticas e/ou econômicas. É parte de sua história de desenvolvimento a ocorrência de vários tipos de conflitos. 
Dentro do que foi exposto no sentido do posicionamento do que representam os CBHs no momento atual dos recursos hídricos no país, é importante situar como pode ser compreendida a particularidade do CBHVelhas. Essa medida é importante pois pode caracterizar como que o comitê pode ser estudado, criticado e possivelmente desenvolvido, porém dentro de um contexto maior, contemporâneo. É importante salientar que o CBHVelhas não possui, essencialmente, nenhuma ação de gestão que poderia ser considerada como "diferenciada". Ao contrário, suas práticas remetem constantemente ao que se tem realizado em CBHs ao redor do mundo ou do próprio Brasil. Um problema constatado é que a maioria dos processos decisórios acontece em termos de considerações políticas e/ou econômicas de curto prazo que desmerecem arranjos sociais que são inerentemente de longo prazo (integração institucional, participação e democratização das arenas consultivas etc). O caso das dificuldades para a instalação de subcomitês realmente operacionais no território da bacia é um exemplo a ser considerado, visto que muitas vezes não há um suporte administrativo para que os mesmos atuem.

\section{Considerações Finais}

Ao analisar o atual modelo de gestão das águas, que adota o modelo descentralizado, participativo e integrado, esse estudo buscou mostrar sobre a nova gestão da política de gestão das águas, com ênfase na descentralização relacionada ao comitê de bacia, especificamente do comitê de bacia do rio das Velhas. Verificou-se a necessidade da participação do comitê para o fortalecimento da efetiva implantação do modelo descentralizado e para a consolidação do processo de tomada de decisão e da governança da água. Há uma carência no que se refere ao modelo de gestão participativa para que o processo se concretize.

De acordo com Lopes e Teixeira (2011), apesar da grande inovação trazida por esse novo modelo de gestão descentralizada, a instalação de um comitê não significa que ele esteja atuando com eficiência. $\mathrm{O}$ funcionamento efetivo dos Comitês de Bacias Hidrográficas necessita de modificações profundas no âmbito cultural e administrativo do estado brasileiro. No entanto, observa-se que a criação dos comitês é de suma importância para que políticas públicas sejam desenvolvidas, proporcionando, assim, uma gestão eficaz dos recursos hídricos no Brasil.

Sugere-se realizar outras pesquisas nos diversos comitês de bacias hidrográficas, de forma que possa verificar inovações e/ou deficiências desses comitês, contribuindo assim para a efetividade da gestão descentralizada dos recursos hídricos no Brasil. É importante também realizar estudos mais aprofundados, no que se refere às legislações, como por exemplo análises do regimento interno, deliberações e registros das reuniões (ATA) desses comitês, inclusive do comitê da bacia hidrográfica do rio das Velhas.

\section{Agradecimentos}

Os autores agradecem à Universidade Federal de Itajubá- UNIFEI, à Agência Nacional de águas- ANA, à Coordenação de Aperfeiçoamento de Pessoal de Nível Superior- CAPES e ao Programa de Mestrado Profissional em Rede Nacional em Gestão e Regulação dos Recursos Hídricos - ProfÁgua, projeto CAPES/ANA.

\section{Referências}

ANA. (2011). Cuidando das águas: soluções para melhorar a qualidade dos recursos hídricos. Programa das Nações Unidas para o Meio Ambiente. Agência nacional de águas - ANA. www.ana.gov.br

Brasil. (1990). Lei $\mathrm{n}^{\mathrm{o}}$ 9.433. Institui a Política Nacional de Recursos Hídricos, cria o Sistema Nacional de Gerenciamento de Recursos Hídricos. http://www.planalto.gov.br/ccivil_03/leis/19433.htm.

Campos, V. N. O. \& Fracalanza, A. P. (2010). Governança das águas no Brasil: conflitos pela apropriação d'água e a busca da integração como consenso. $R$. Ambiente \& Sociedade., Campinas.

CBH Rio das Velhas. (2021). Apresentação. https://cbhvelhas.org.br/apresentacao. 
CBH Rio Das Velhas. (2021). Atualização do Plano Diretor de Recursos Hídricos. https://cbhvelhas.org.br/plano-diretor-cbh-velhas.

CBH Rio Das Velhas. (2021). https://cbhvelhas.org.br.

Denny, D. M. T. et. al. (2020). Comitês de Bacia Hidrográfica: Governança e efetividade na Gestão de Recursos Hídricos. R. gest. Sust. Ambiente., Florianópolis. 9(4), 227-247.

Instituto Brasileiro de Geografia e Estatística - IBGE. (2010). Portal de mapas do IBGE.

Instituto Mineiro de Gestão das Águas - IGAM. (2021). Portal do Comitês. http://comites.igam.mg.gov.br/comites-estaduais-mg/sf5-cbh-rio-das-velhas.

Lemos, R. S., \& Magalhães, A. P. (2019). Dinâmica Territorial, transformações ambientais e implicações no manancial de abastecimento público da Região Metropolitana de Belo Horizonte-bacia hidrográfica do rio das Velhas. R. GeoTextos.

Lemos, R. S. \& Rocha, R. M. L. (2013). Os processos de outorga de direito de uso de recursos hídricos em Minas Gerais: uma releitura a partir da experiência do comitê da Bacia Hidrográfica do rio das Velhas. XX Simpósio Brasileiro de Recursos Hídricos.

Lopes, M. M. L. \& Teixeira, D. (2011). O Processo de Criação e Consolidação dos Comitês de Bacias Hidrográficas para Gestão dos Recursos Hídricos. Revista Brasileira Multidisciplinar, 14(1), 7-16. https://doi.org/10.25061/2527-2675/.

Magalhães Junior, H. \& Lopes, F. W. A. (2017). Levantamento e análise dos conflitos pelos usos da água na bacia do Ribeirão da Prata-MG. R. Ibero Americana de Ciências Ambientais.

Minas Gerais. (1988). Decreto $\mathrm{n}^{\mathrm{o}}$ 36.692. Institui o Comitê da Bacia Hidrográfica do rio das Velhas. https://www.almg.gov.br/consulte/legislacao/completa/completa.html?tipo=DEC\&num=39692\&comp=\&ano=1998.

Minas Gerais. (1999). Lei no 13.199. Dispõe sobre a Política Estadual de Recursos Hídricos e dá outras providências. https://progestao.ana.gov.br/portal/progestao/panorama-dos-estados/mg/lei-no13-199-99_mg.pdf.

Moreira, J. F., Vianna, P. C. G., Andrade, M. O. \& Da Silva Filho, V. F. (2018). Gestão dos recursos hídricos e conflito: estudo de caso da comunidade Mãe D’água, na bacia $\quad$ hidrográfica $\quad$ Piranhas-Açu. $\quad$ Gaia $\quad$ Scientia. $\quad$ 12(3). 1268.2018v12n3.36681. https://periodicos.ufpb.br/index.php/gaia/article/view/36681.

OCDE. (2015). Principles on Water Governance. https://www.oecd.org/cfe/regionaldevelopment/OECD-Principles-Water-portuguese.pdf

Plano diretor de Recursos Hídricos rio da Velhas. (2015). https://cdn.agenciapeixevivo.org.br/media/2020/06/RESUMO-EXECUTIVO-PDRH-VELHAS$2015 /$.

Ribeiro, J., Lemos, R. S., Cota, G., Magalhães, A. \& Peron, G. (2018). A abordagem de conflitos pelo uso da água na Gestão de Recursos Hídricos - reflexões a partir do contexto da bacia do alto rio das Velhas/MG. Caminhos De Geografia, 19(68), 343-360. https://doi.org/10.14393/RCG196823.

Theodoro, H. D. (2017). Análise da gestão de recursos hídricos: um estudo de caso do comitê da bacia do Rio das Velhas. Dissertação de doutorado., Universidade Federal de Minas Gerais.

Theodoro, H. D., Nascimento, N. O. \& Heller, L. (2016). A institucionalização da Gestão de Recursos Hídricos na Bacia Hidrográfica do Rio das Velhas, Minas Gerais, Brasil, sob a ótica democrática e participativa. R. Eletr. Cient, 2 (2), 159-173.

Trindade, L. L., Scheibe, L. F. \& Ribeiro, W. C. (2018). A governança da água: o caso dos comitês dos rios Chapecó e Irani- SC. Revista Geosul., 33(68), 3657.

Tundisi, J. G., Matsumura-Tundisi, T. (2011). Recursos Hídricos no Século XXI. Oficina de Textos. 